\title{
Modifying Cancer-Related Fatigue by Optimizing Sleep Quality
}

\author{
Ann Malone Berger, PhD, RN, AOCN, ${ }^{a}$ and Sandra A. Mitchell, CRNP, MScN, AOCN, ${ }^{\mathrm{b}}$ Omaha, Nebraska, \\ and Bethesda, Maryland
}

\section{Key Words}

Cancer, fatigue, sleep disturbances, daytime sleepiness, symptom management, evidence-based practice

\begin{abstract}
Cancer-related fatigue is reported by patients to be the most distressing and persistent symptom experienced during and after treatment. Unrelieved fatigue often accompanies other symptoms and leads to decreased physical functioning and lower health-related quality of life. Various factors, including daytime sleepiness and sleep disturbances, have been reported to influence perceptions of fatigue. This article shares current knowledge about the relationships among cancer-related fatigue, sleep disturbances, and daytime sleepiness, and makes recommendations for routine screening, assessment, and interventions to modify fatigue through optimizing sleep quality in adult cancer patients. Evidence is reviewed for nonpharmacologic and pharmacologic interventions for optimizing sleep quality in patients with acute or chronic insomnia secondary to medical illnesses, including cancer. A summary of interventions is presented that focuses on optimizing sleep quality in attempt to lower fatigue. These interventions may be helpful for adult cancer patients experiencing insomnia but will require further testing to establish their efficacy in this population. Recommendations for research are provided, including the need to increase knowledge on the relationships among fatigue, sleep disturbances, daytime sleepiness, and other symptoms in various disease sites, stages, and treatments of cancer and the need for further testing of the measurements used for the evaluation of sleep quality in clinical practice and research. (JNCCN 2008;6:3-13)
\end{abstract}

Cancer-related fatigue (CRF) has been identified as the most prevalent and distressing, yet underrecognized symptom associated with cancer and cancer treatments in adults. ${ }^{1}$ Clinical assessment of CRF has increased during the past decade. A 0 to 10 visual analog scale, such as the one incorporated in the National Comprehensive Cancer Network (NCCN) Cancer-Related Fatigue Clinical Practice Guidelines in Oncology (in this issue), has been adopted to assess this symptom in many clinical settings. ${ }^{2}$ One major limiting factor in initiating assessment has been the lack of evidence for interventions to relieve a patient's self-reported CRF. The NCCN guidelines direct clinicians to assess treatable contributing factors, including pain, emotional distress, anemia, sleep disturbances, nutritional status, activity level, and comorbid illnesses. The guidelines also provide clinicians with information to relieve CRF through enhancing activity level and psychosocial interventions.

Clinicians may feel less prepared to intervene when an assessment shows a patient is experiencing sleep disturbances in addition to CRF. Most clinicians are unaware of how to optimize sleep quality when it presents alone or in combination with CRF and other symptoms. Therefore, this article shares current knowledge about the relationships among CRF, sleep disturbances, and daytime sleepiness, and makes recommendations for routine screening, assessment, and interventions to modify fatigue through optimizing sleep quality in adult cancer patients. Current knowledge linking CRF with sleep disturbances and daytime sleepiness is summarized, followed by a review of evidence-based nonpharmacologic and pharmacologic interventions to optimize sleep quality and impact daytime sleepiness and CRF. A summary of recommendations is provided for practice and research to optimize sleep quality and modify fatigue in adult cancer patients. 
Berger and Mitchell

\section{Fatigue, Sleep Disturbances, and Daytime Sleepiness in Cancer Patients}

Fatigue is defined by the NCCN as a "distressing, persistent, subjective sense of tiredness or exhaustion related to cancer or cancer treatment that is not proportional to recent activity and interferes with usual functioning." Fatigue is reported by most cancer patients who have undergone surgery, chemotherapy, or radiation therapy, ${ }^{3}$ or have been treated with hematopoietic stem cell transplantation, hormonal therapy, or a biologic response modifier, ${ }^{4}$ often persisting for months or years beyond completion of treatment. Fatigue rarely occurs alone; more commonly it is reported as one of several symptoms that occur in clusters. ${ }^{5}$ This multidimensional subjective symptom has physical, emotional, sensory, and cognitive dimensions that impact functioning. Fatigue is referred to as acute when it lasts less than 4 weeks and chronic when it lasts 1 to 6 months or longer. ${ }^{3}$

Similar to fatigue, sleep disturbances, of which insomnia is the most prevalent, have been underrecognized and undertreated in cancer patients. ${ }^{6}$ Insomnia has been reported in 30\% to $50 \%$ of cancer patients, ${ }^{7}$ more than twice the incidence in the general public. Insomnia refers to "complaints of difficulty initiating or maintaining sleep or non-restorative sleep which lasts for at least one month and which causes clinically significant distress or impairment in social, occupational, or other important areas of functioning." Diagnostic criteria for insomnia include associated daytime fatigue and significant fatigue-related distress. Quality sleep is defined as the absence of the above complaints, distress, and impairments.

Assessment is the first step in managing sleep disturbances. ${ }^{9}$ A screening tool to detect individuals with these complaints, such as the Clinical Sleep Assessment for Adults ${ }^{10}$ or the Insomnia Severity Index, ${ }^{11}$ must be used in the clinical setting. When the screen is positive, sleep patterns that should be assessed include time in bed, total sleep time, sleeponset latency, number of awakenings, number of minutes awake or percent of time awake after sleep onset, daytime napping, excessive daytime sleepiness, sleep quality, and sleep efficiency. ${ }^{12}$ Further assessment of risk factors for sleep disorders is also indicated when the screen is positive, with a focus on other symptoms, comorbid illnesses, and current medications. ${ }^{13}$ Recommendations for a standard research assessment of insomnia disorders have been identified, and include definitions and diagnoses of insomnia and comorbid conditions; measures of sleep and insomnia, including qualitative insomnia measures, diary, polysomnography, and actigraphy; and measures of the waking correlates and consequences of insomnia disorders. ${ }^{14}$

The Conceptual Model of Impaired Sleep ${ }^{15}$ posits that impaired sleep can be categorized as either sleep deprivation resulting from an inadequate amount of sleep or sleep disruption that occurs secondary to fragmented sleep during the sleep period (Figure 1). Sleep deprivation is often the result of lifestyle and developmental factors, whereas sleep disruption is often caused by health-related conditions, including cancer. Another model, known as the 3P model, suggests that impaired sleep is related to numerous predisposing, precipitating, or perpetuating factors. ${ }^{16}$ The specific causes of impaired sleep in patients with cancer have not been determined, but factors that contribute to disturbances in sleep regulation have been identified in healthy adults ${ }^{17}$ and patients with cancer. ${ }^{18} \mathrm{~A}$ neuroendocrine-based regulatory fatigue model has hypothesized that a shared origin may exist for several symptoms, including impaired sleep, fatigue, and depression, in specific cancer populations. ${ }^{19}$ This model and several lines of study provide evidence that sleep disturbances, fatigue, and other symptoms, such as asthenia and problems with mental concentration, in cancer patients may be linked to hypothalamic-pituitary-adrenal axis overactivity and excess secretion of corticotropin-releasing factor, adrenocorticotropinreleasing hormone, and cortisol, together with diurnal variations in immunoregulatory cytokine levels and altered circadian rhythmicity. ${ }^{20-25}$ Growing evidence suggests that proinflammatory cytokines play a role in the origin of several chemotherapy-related symptoms. ${ }^{26}$ Impaired sleep has also been linked to numerous adverse Health Related Quality of Life (HRQOL) outcomes in physiological, cognitivebehavioral, emotional, and social domains, as shown in Figure 1..$^{15,27}$

Common sleep disorders in adults include insomnia, sleep-related breathing disorders, sleep-related movement disorders, and parasomnias. ${ }^{28,29}$ Insomnia is a heterogeneous disorder that includes primary insomnias for which no other cause is known. ${ }^{28}$ Primary insomnia has been termed psychophysiologic (heightened arousal and learned sleep-preventing 


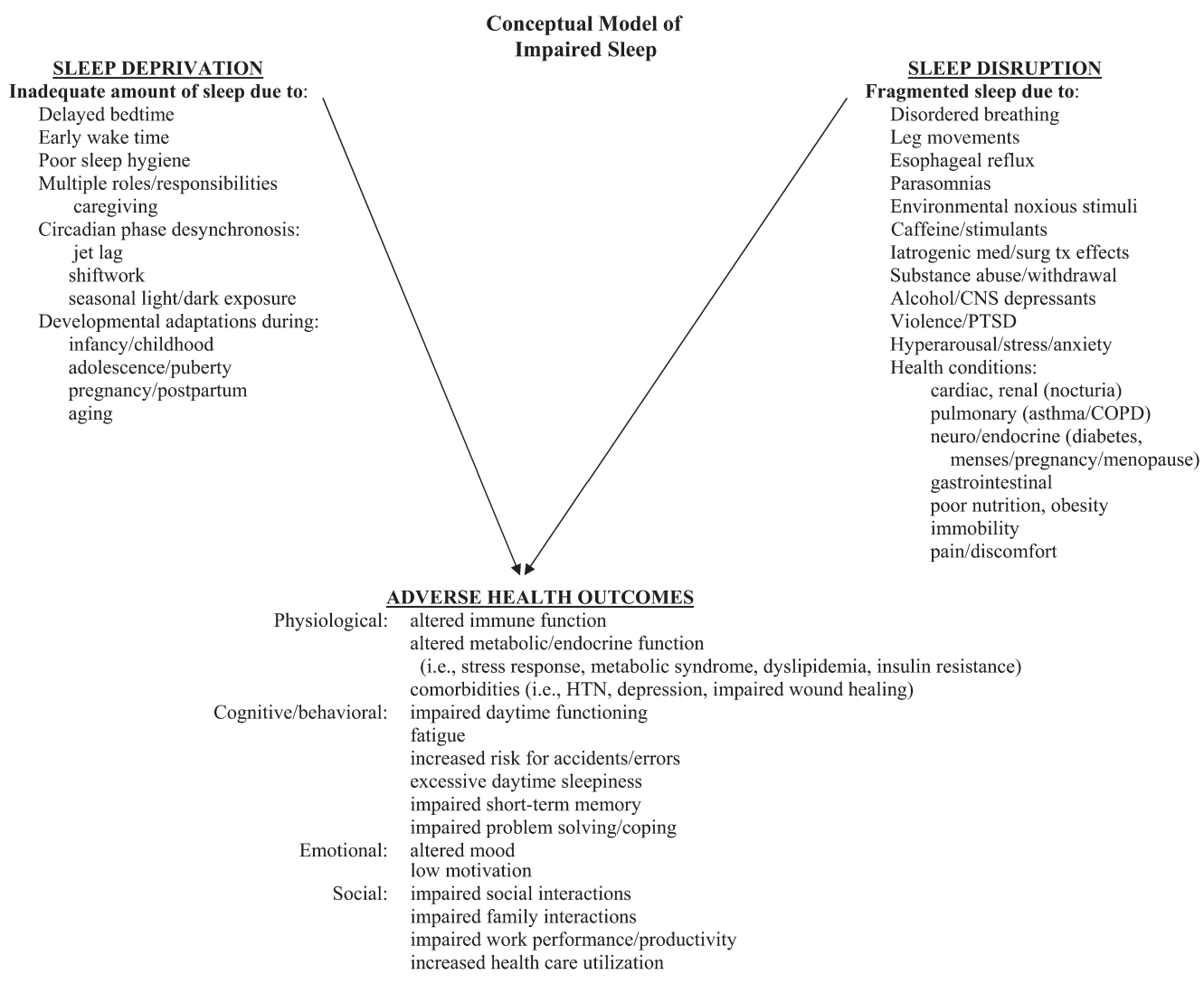

Figure 1 The Conceptual Model of Impaired Sleep ${ }^{15}$.

Abbreviations: CNS, central nervous system; COPD, chronic obstructive pulmonary disease; HTN, hypertension; PTSD, posttraumatic stress disorder.

From Lee KA. Impaired sleep. In: Carrieri-Kohlman V, Lindsey A, West C, eds. Pathophysiological Phenomena in Nursing. 3rd ed. St. Louis, MO: Saunders; 2003:364, (C) Elsevier 2003.

associations); physiologic (subjective reports confirmed by objective sleep measures); and idiopathic (linked to childhood onset and a chronic inability to obtain adequate sleep). The prevalence of each type of primary insomnia has not been routinely assessed or reported in patients newly diagnosed with cancer. Another group of insomnias, traditionally referred to as secondary insomnias but recently termed comorbid insomnias, include insomnia associated with other medical disorders, such as cancer..$^{30}$

Assessment for depression is imperative, because sleep disturbances and fatigue are common manifestations of depression. ${ }^{31,32}$ Insomnia can be transient, transient recurring, or chronic in nature (lasting 6 months). Daytime sleepiness has been described as the likelihood of a person falling asleep during 8 phases of daily life. ${ }^{33}$ Daytime sleepiness is a frequent complaint among cancer patients who report poor sleep, but few studies have described the prevalence and consequences of daytime sleepiness in patients with cancer.
Evidence shows that fatigue, sleep disturbances, and daytime sleepiness are associated with each other and other symptoms, but a clear understanding of the relationships among them has not been established in cancer patients. ${ }^{34,35}$ Recent review articles have described relationships among these variables, including the occurrence of symptom clusters, based on studies at different points along the cancer trajectory., ${ }^{1,2,36-41}$ Studies have most commonly included women with breast cancer at various times along the cancer trajectory. Consistent relationships have been found between higher CRF and more disturbed sleep before, ${ }^{42-44}$ during, ${ }^{45,46}$ and after ${ }^{47-50}$ completion of chemotherapy treatments. Moderate to severe sleep maintenance problems in patients treated with chemotherapy, indicated by increased number and duration of nighttime awakenings, have been documented using wrist actigraphy. ${ }^{45,46}$ The relationship between fatigue and disturbed sleep in numerous dimensions has been reinforced and complimented by subjects' perceptions of their sleep as measured with reliable 
Berger and Mitchell

and valid tools, such as the Pittsburgh Sleep Quality Index..$^{51} \mathrm{~A}$ link between increased fatigue and sleep disturbances (per actigraphy) was also found in outpatients undergoing radiation therapy for bone metastasis. ${ }^{52}$ Pain treatment with strong opioids, a feeling of hopelessness, and interference of pain with mood significantly influenced sleep quality in patients with advanced cancer. ${ }^{53}$

Higher self-reported daytime dysfunction has been found to be associated with more disturbed sleep and higher fatigue in the 48 hours before the first adjuvant breast cancer chemotherapy treatment. ${ }^{42,43}$ Daytime sleepiness has seldom been reported in relation to sleep quality in cancer patients. A recent study reported a relationship between more disturbed sleep quality and higher daytime sleepiness during adjuvant breast cancer chemotherapy, as measured by the Epworth Sleepiness Scale. ${ }^{46}$

Higher levels of CRF before and during chemotherapy treatments also have been shown in patients with breast cancer to be related to less robust circadian activity rhythms. ${ }^{40,42,43,45,54-56}$ Components of less robust rhythms include disrupted sleep, low daytime activity levels, and a dampened range of activity over 24-hour periods. Aberrant circadian rhythms were linked to higher fatigue and marked disruption of function and HRQOL in patients with advanced cancer. ${ }^{57,58}$ Higher fatigue has also been identified as part of symptom clusters that include menopausal symptoms such as a hot flashes, vaginal dryness, and decreased libido; $;{ }^{59}$ pain and insomnia; ${ }^{60}$ disturbed sleep and depression; ${ }^{29,38}$ disturbed sleep, pain, and anxiety/depression, ${ }^{52}$ depression, disturbed sleep, and cognitive impairment; ${ }^{61}$ and depressive symptoms and impaired functional status. ${ }^{62}$ Understanding the relationships between and among symptoms has been challenging for clinicians and researchers.

\section{Interventions to Optimize Sleep Quality and Daytime Functioning}

\section{Evidence-Based Practice Guidelines}

Symptom management is a key aspect of the scope of practice of the oncology nurse and an important responsibility of the entire healthcare team. The contemporary healthcare delivery system holds all clinicians accountable to provide evidence-based care that is safe and cost-effective. The American Academy of Sleep Medicine (AASM) recently published an updated summary of the evidence ${ }^{63}$ and evidence-based practice parameters ${ }^{64}$ relative to behavioral and psychological treatments for primary and secondary (i.e., comorbid) insomnia. The summary did not address any evidence relative to pharmacologic agents. The AASM classification of evidence, adapted from Sackett, ${ }^{65}$ was used to grade evidence from peerreviewed scientific literature, and recommendations for practice were proposed.

The Oncology Nursing Society (ONS) developed a similar schema for grading the strength of evidence by adapting the British Medical Journal (BMJ) Clinical Evidence model. ${ }^{66,67}$ The report entitled, ONS Putting Evidence into Practice, refers to these resources for improving patient outcomes as "ONS PEP" resources. ${ }^{68}$ All nonpharmacologic and pharmacologic interventions for both fatigue and sleep-wake disturbances that had been tested in cancer patients and published by December 2005 were critically reviewed, and the overall strength of the evidence was graded. ${ }^{69,70}$ Table 1 summarizes the grading schemas used by AASM and ONS to analyze the evidence supporting the effectiveness of interventions for managing fatigue and sleep disturbances.

\section{Nonpharmacologic Interventions}

Psychological and cognitive-behavioral therapies encompass a broad group of sleep interventions that involve attenuating physiologic arousal and changing negative thought processes and attitudes about one's ability to fall asleep, stay asleep, get enough sleep, and function during the day. ${ }^{71,72}$

These therapies are designed to assist with sleep initiation and maintenance. Table 2 summarizes current evidence for cognitive-behavioral interventions and strategies. ${ }^{73}$ The 2006 AASM practice parameters rated psychological and behavioral interventions as effective, and recommended them as "Standard" for the treatment of chronic primary and secondary (comorbid) insomnia. ${ }^{64}$ This recommendation for secondary insomnia was based on 11 studies that evaluated the effects of treatment for insomnia associated with another medical or psychiatric disorder, including 4 randomized controlled trials with either level $1^{74,75}$ or level $2^{76,77}$ evidence.

AASM practice parameters also recommended as standard 3 specific therapies for chronic insomnia: stimulus-control therapy, relaxation training, and cognitive behavior therapy (with or without relaxation therapy). AASM rated the following therapies as "Guideline" for chronic insomnia: sleep restriction, 
Cancer-Related Fatigue and Sleep Quality

multicomponent therapy, paradoxical intention, and biofeedback. "Insufficient Evidence" recommended sleep hygiene education as a single therapy or when incorporated into multicomponent approaches. ${ }^{64}$

The ONS PEP resources organized sleep-wake interventions that were tested in cancer patients into 4 categories: cognitive-behavioral, complementary, psychoeducational, and exercise therapies. ${ }^{70}$ No intervention was categorized as "Recommended for Practice" or "Likely to be Effective." Several sleep interventions reporting a positive impact on sleep were classified as "Effectiveness Not Established." No sleep intervention was classified as "Effectiveness Unlikely" or "Not Recommended for Practice." 67

The ONS PEP resources rated 5 of the cognitivebehavioral sleep intervention studies referred to above as "Likely to be Effective" for reducing fatigue in cancer patients. ${ }^{78-82}$ Lower fatigue in cancer patients was also reported as a result of sleep interventions from each of the other categories of sleep interventions, including complementary, ${ }^{83}$ psychoeducational, ${ }^{84}$ and exercise. ${ }^{85}$ These interventions have been shown to be effective when delivered either individually or in group settings.

\section{Pharmacologic Interventions}

Numerous pharmacologic approaches are available to enhance sleep ${ }^{86}$ but have not been examined in clinical trials with cancer patients. Although commonly prescribed, data specific to the use of benzodiazepine and nonbenzodiazepine hypnotic drugs, sedating antidepressants, antipsychotics/neuroleptics, selected melatonin receptor agonists, and over-the-counter agents, including antihistamines, melatonin, and valerian, are currently insufficient to promote sleep quality in patients with cancer, including those at end of life. ${ }^{87,88}$

Meta-analyses suggest that hypnotic agents improve the quality and amount of sleep and reduce night awakenings in older adults with primary insomnia. ${ }^{89-91}$ These benefits are outweighed by the associated adverse cognitive and psychomotor events, and daytime fatigue and sleepiness. ${ }^{92}$ Pharmacologic agents indicated to improve sleep quality were categorized by the ONS PEP resources in the category of "Benefits Balanced with Harms," indicating that clinicians should evaluate the efficacy and safety of each prescribed agent to improve sleep in patients with cancer. ${ }^{70}$
Several other pharmacologic therapies have shown potential to impact positively the cluster that includes poor sleep quality, fatigue, mood disturbance, and daytime sleepiness. Although agents to promote daytime functioning, such as bupropion sustained-release, methylphenidate, and donepezil, have been shown to improve fatigue, mood, and HRQOL in patients with cancer, ${ }^{93-102}$ effects on sleep quality were not evaluated.

Similarly, in 3 large randomized trials examining the effects of paroxetine in cancer patients during treatment, sleep quality was not measured. ${ }^{103-105}$ However, in a small single-arm pilot study, paroxetine had positive effects on fatigue, mood, symptom distress, and sleep quality in women who had completed treatment for localized breast cancer and were experiencing hot flashes. ${ }^{106}$ Two case reports and expert opinion identify benefits for modafinil in terms of sleep quality, symptom distress, and fatigue. ${ }^{107-111}$ Although not approved by the US Food and Drug Administration (FDA), amisulpride has shown early promise in managing daytime sleepiness and fatigue secondary to sedating medications. ${ }^{90,91,112}$

\section{Recommendations for Practice}

Routine screening for sleep disturbances and fatigue should be integrated into clinical oncology practice. Positive screens must be followed up with assessment of risk factors for disturbed sleep, including other related symptoms, mood disturbances, and comorbid illness. ${ }^{2}$ Referrals to sleep specialists are indicated when the clinical screen and assessment indicate the presence of sleep disorders or chronic insomnia, and when insomnia is refractory to usual intervention strategies. Oncology clinicians must be educated on basic strategies to recommend when transient or transient recurring insomnia is present. Although efficacy of the nonpharmacologic interventions presented in Table 2 awaits results of several ongoing randomized controlled trials, these interventions have been supported for introduction in clinical practice to treat chronic primary and secondary (comorbid) insomnia and fatigue, and optimize daytime function. ${ }^{64,69,70}$ Although a wide variety of pharmacologic options are available to improve sleep quality, many are associated with adverse side effects. Little empiric evidence is available on the use of these agents in patients with cancer. Clinicians must be aware of a recent FDA warning about potential risks associated with sedative-hypnotic drugs, such as severe allergic reactions and complex sleep-related 
Berger and Mitchell

\begin{tabular}{|c|c|c|c|c|}
\hline \multirow{2}{*}{$\begin{array}{l}\text { Highest } \\
\text { Level of } \\
\text { Evidence }\end{array}$} & \multicolumn{2}{|c|}{$\begin{array}{l}\text { American Academy of Sleep } \\
\text { Medicine (AASM)* }\end{array}$} & \multicolumn{2}{|c|}{$\begin{array}{l}\text { Oncology Nursing Society Putting Evidence } \\
\text { into Practice (ONS PEP) }\end{array}$} \\
\hline & Standard & $\begin{array}{l}\text { A generally accepted patient } \\
\text { care strategy that reflects a } \\
\text { high degree of clinical certainty, } \\
\text { supported by the highest level } \\
\text { of evidence (a single rigorously } \\
\text { conducted randomized } \\
\text { controlled trial [RCT]or } \\
\text { consistent evidence } \\
\text { from several RCTs) }\end{array}$ & $\begin{array}{l}\text { Recommended } \\
\text { for practice }\end{array}$ & $\begin{array}{l}\text { Interventions for which effective- } \\
\text { ness has been demonstrated by } \\
\text { strong evidence from rigorously } \\
\text { conducted studies, meta-analyses, } \\
\text { or systematic reviews, and for } \\
\text { which expectation of harm sis } \\
\text { small compared with the benefits. }\end{array}$ \\
\hline & \multirow[t]{2}{*}{ Guideline } & \multirow[t]{2}{*}{$\begin{array}{l}\text { A patient care strategy } \\
\text { that reflects a moderate } \\
\text { degree of clinical certainty, } \\
\text { supported by evidence (from } \\
\text { several RCTs or by consistent } \\
\text { evidence from several } \\
\text { non-randomized studies) }\end{array}$} & $\begin{array}{l}\text { Likely to be } \\
\text { effective }\end{array}$ & $\begin{array}{l}\text { Interventions for which effective- } \\
\text { ness has been demonstrated by } \\
\text { supportive evidence from a single } \\
\text { rigorously conducted controlled } \\
\text { trial, consistent supportive } \\
\text { evidence from well-designed } \\
\text { controlled trials using small samples, } \\
\text { or guidelines developed from } \\
\text { evidence and supported by expert } \\
\text { opinion. }\end{array}$ \\
\hline & & & $\begin{array}{l}\text { Not } \\
\text { recommended } \\
\text { for practice }\end{array}$ & $\begin{array}{l}\text { Interventions for which lack of } \\
\text { effectiveness or harmfulness has } \\
\text { been demonstrated by strong } \\
\text { evidence from rigorously conducted } \\
\text { studies, meta-analyses, or system- } \\
\text { atic reviews, or interventions } \\
\text { where the costs, burden, or harms } \\
\text { associated with the intervention } \\
\text { exceed anticipated benefit. }\end{array}$ \\
\hline & \multirow[t]{3}{*}{ Option } & \multirow[t]{3}{*}{$\begin{array}{l}\text { A patient care strategy that } \\
\text { reflects uncertain clinical use. } \\
\text { The term option implies either } \\
\text { inconclusive or conflicting } \\
\text { evidence or conflicting } \\
\text { expert opinion }\end{array}$} & $\begin{array}{l}\text { Benefits } \\
\text { balanced } \\
\text { with harms }\end{array}$ & $\begin{array}{l}\text { Interventions for which } \\
\text { clinicians and patients should } \\
\text { weigh the beneficial and } \\
\text { harmful effects according to } \\
\text { individual circumstances and } \\
\text { priorities. }\end{array}$ \\
\hline & & & $\begin{array}{l}\text { Effectiveness } \\
\text { not } \\
\text { established }\end{array}$ & $\begin{array}{l}\text { Interventions for which there } \\
\text { are currently insufficient or } \\
\text { conflicting data or data of } \\
\text { inadequate quality, with no } \\
\text { clear indication of harm. }\end{array}$ \\
\hline $\begin{array}{l}\text { Lowest } \\
\text { Level of } \\
\text { Evidence }\end{array}$ & & & $\begin{array}{l}\text { Effectiveness } \\
\text { unlikely }\end{array}$ & $\begin{array}{l}\text { Interventions for which lack of } \\
\text { effectiveness has been demon- } \\
\text { strated by negative evidence } \\
\text { from a single rigorously con- } \\
\text { ducted controlled trial, consis- } \\
\text { tent negative evidence from } \\
\text { well-designed controlled trials } \\
\text { using small samples, or guide- } \\
\text { lines developed from evidence } \\
\text { and supported by expert opinion. }\end{array}$ \\
\hline
\end{tabular}

Highest Level of Evidence

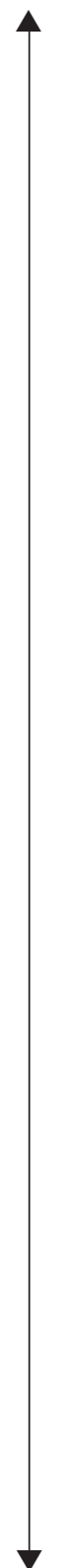

Lowest Level of Evidence

*Based information from Morgenthaler R, Kramer M, Alessi C, et al. Practice parameters for the psychological and behavioral threatment of insomnia: an update. An American Academy of Sleep Medicine report. Sleep 2006;29:1415-1419.

${ }^{\dagger}$ Mitchell SA, Friese CR. ONS Putting Evidence into Practice. Available at:

http://www.ons.org/outcomes/tables/documents/woevidence.pdf. Accessed September 26, 2007. 
Cancer-Related Fatigue and Sleep Quality

\begin{tabular}{|c|c|c|c|c|}
\hline $\begin{array}{l}\text { Intervention } \\
\text { for Insomnia }\end{array}$ & Rationale & $\begin{array}{l}\text { Type of } \\
\text { Insomnia }\end{array}$ & Level of Evidence* ${ }^{\dagger}$ & Components of Intervention ${ }^{\ddagger}$ \\
\hline Stimulus control & $\begin{array}{l}\text { Trains person to } \\
\text { reassociate the bed } \\
\text { and bedroom with } \\
\text { sleep and to reestablish } \\
\text { a consistent sleep-wake } \\
\text { schedule }\end{array}$ & Chronic & $\begin{array}{l}\text { Effectiveness } \\
\text { not established }^{\dagger}\end{array}$ & $\begin{array}{l}\text { - Use the bed only for sleep and sexual activity. } \\
\text { - If unable to fall asleep within } 20 \text { minutes, } \\
\text { get out of bed and go to a dark quiet place } \\
\text { to relax until ready to fall asleep. } \\
\text { - After returning to bed, get out of bed if } \\
\text { unable to fall asleep within } 20 \text { minutes. } \\
\text { - Go to bed only when you are feeling sleepy } \\
\text { and ready to sleep at a consistent time } \\
\text { each night. } \\
\text { - Get up each morning at a consistent time no } \\
\text { matter how much (or how little) you slept the } \\
\text { night before. } \\
\text { - Do not take naps during the day. } \\
\text { - Do not watch the clock or panic if you wake } \\
\text { up during the night. }\end{array}$ \\
\hline $\begin{array}{l}\text { Relaxation } \\
\text { training }\end{array}$ & $\begin{array}{l}\text { Reduces somatic } \\
\text { tension and/or } \\
\text { intrusive thoughts at } \\
\text { bedtime that interfere } \\
\text { with sleep }\end{array}$ & Chronic & $\begin{array}{l}\text { Standard* } \\
\text { Efficacy not } \\
\text { established }^{\dagger}\end{array}$ & $\begin{array}{l}\text { Within } 2 \text { hours of bedtime, use: warm bath or } \\
\text { shower, massage, reading, listening to soft } \\
\text { music, muscle relaxation activities. }\end{array}$ \\
\hline $\begin{array}{l}\text { Sleep } \\
\text { restriction }\end{array}$ & $\begin{array}{l}\text { Limits the amount } \\
\text { of time in bed to } \\
\text { more closely } \\
\text { approximate the } \\
\text { actual time spent } \\
\text { sleeping }\end{array}$ & Chronic & $\begin{array}{l}\text { Guideline* }^{*} \\
\text { Efficacy not } \\
\text { established }\end{array}$ & $\begin{array}{l}\text { - Set limits on the amount of time in bed to } \\
\text { actual time spent asleep. } \\
\text { - Calculate total sleep time (TST) for at least } 5 \\
\text { nights by dividing the total time asleep in } \\
\text { bed by the total time spend in bed; multiply } \\
\text { by } 100 \text {. If } 85 \% \text { or more, continue to spend } \\
\text { the same amount of total time in bed. If }<85 \% \text {, } \\
\text { set the beginning total time in bed to equal } \\
\text { the TST. Once the number is } 85 \% \text { or higher } \\
\text { for } 5 \text { nights, increase time in bed by } \\
15 \text { minutes by going to bed } 15 \text { minutes } \\
\text { earlier. If the number drops below } 85 \% \text {, } \\
\text { then decrease time in bed by } \\
15 \text { minutes. }\end{array}$ \\
\hline Sleep hygiene & $\begin{array}{l}\text { Teaches individuals a } \\
\text { variety of health } \\
\text { practices and } \\
\text { environmental factors } \\
\text { that support sleep } \\
\text { through their salutary } \\
\text { effects on sympathetic } \\
\text { nervous system } \\
\text { stimulation, circadian } \\
\text { rhythms, and } \\
\text { sleep-wake cycle }\end{array}$ & Not specified & $\begin{array}{l}\text { Effectiveness } \\
\text { not established }^{\dagger}\end{array}$ & $\begin{array}{l}\text { - Establish a regular wake-up routine. Do not } \\
\text { oversleep in an attempt to "catch up" on } \\
\text { lost sleep. } \\
\text { - Get exposure to bright light (sunlight is best) } \\
\text { as early as possible after waking. } \\
\text { - During the day, follow a schedule for meals, } \\
\text { exercise, wake time, and bedtime. } \\
\text { - Complete exercise within } 2 \text { hours of bedtime. } \\
\text { - Limit/eliminate consumption of caffeine and } \\
\text { - alcohol within } 4 \text { hours of bedtime. } \\
\text { - } \text { Kevelop a nightly prebedtime routine. } \\
\text { phones; no computer or pets; use light } \\
\text { clothing and covers. } \\
\text { - Replace mattress every } 10 \text { to } 12 \text { years. }\end{array}$ \\
\hline
\end{tabular}

*Based on information from Morgenthaler T, Kramer M, Alessi C, et al. Practice parameters for the psychological and behavioral treatment of insomnia: an update. An American Academy of Sleep Medicine report. Sleep 2006;29:1415-1419.

${ }^{\dagger}$ Based on information from Page MS, Berger AM, Johnson LB. Putting evidence into practice: evidence-based interventions for sleep-wake disturbances. Clin J Oncol Nurs 2006;10:753-767.

‡Based on information from Szuba MP, Kloss JE, Dinges DF. Insomnia Principles and Management. New York, NY: Cambridge University Press; 2003. 
Berger and Mitchell

behaviors, including sleep-driving. ${ }^{113}$ A table summarizing the medications commonly used to promote sleep is provided on the National Cancer Institute PDQ (Physician Data Query) Web site. ${ }^{13}$ Prescribing considerations with these classes of agents include increased likelihood of problems with daytime sleepiness, fatigue, withdrawal symptoms, dependency, rebound insomnia, problems with sleep maintenance, memory problems, anticholinergic symptoms, orthostasis, and the potential for drug-drug interactions involving the cytochrome p450 isoenzyme system. ${ }^{114}$ Increased public and professional education on sleep, sleep disturbances, and daytime consequences of sleep loss is recommended.

\section{Recommendations for Research}

Sleep disturbances in cancer patients and their impact on fatigue, daytime sleepiness, other symptoms, functioning, and HRQOL have emerged as recommended areas for research. The proceedings of 2 recent State of the Science conferences have highlighted the priorities for interdisciplinary research of sleep-wake disturbances in patients with chronic primary insomnia and those with cancer. ${ }^{12,30}$ Priority areas for research include evaluating the effectiveness of single-and multicomponent psychological and cognitive-behavioral treatments in not only reducing insomnia but also improving fatigue, daytime function, and HRQOL. Areas of particular focus for researchers include determining the cause of disturbed sleep associated with various tumor sites, disease stages, and treatment regimens; exploring the relationships among symptoms that cluster together with sleep disturbances and fatigue; and improving sleep outcome measures in clinical practice and research trials. ${ }^{12}$ Relevant outcomes in clinical trials of therapies to improve sleep include short-and long-term effectiveness and associated risks/benefits, costs, and patient satisfaction. ${ }^{64}$

\section{Summary}

Increased knowledge and awareness are needed of available, evidence-based interventions to optimize sleep quality and improve fatigue and daytime sleepiness in adult cancer patients. Routine screening, assessment, and referrals can help identify individuals with sleep disturbances. Clinicians are encouraged to use recommended nonpharmacologic and pharmacologic interventions that are designed to optimize sleep quality and modify fatigue during and after cancer treatment.

\section{Acknowledgments}

The authors wish to acknowledge Brett R. Kuhn, PhD, CBSM, for his mentoring, and both Dr. Kuhn and Ms. Margaretta Page, MS, RN, for their careful review of this manuscript.

\section{References}

1. Prue G, Rankin J, Allen J, et al. Cancer-related fatigue: a critical appraisal. Eur J Cancer 2006;42:846-863.

2. Mock V, Abernethy AP, Atkinson A, et al. NCCN Clinical Practice Guidelines in Oncology - Cancer-Related Fatigue, v.2.2007. Available at: http://www.nccn.org/. Accessed September 26, 2007.

3. Piper B. Fatigue. In: Carrieri-Kohlman V, Lindsey A, West C, eds. Pathophysiological Phenomena in Nursing, 3rd ed. St Louis, MO: Saunders; 2003:209-234.

4. Hofman M, Ryan JL, Figueroa-Moseley CD, et al. Cancer-related fatigue: the scale of the problem. Oncologist 2007;12(Suppl 1):4-10.

5. Barsevick AM, Whitmer K, Nail LM, et al. Symptom cluster research: conceptual, design, measurement, and analysis issues. J Pain Symptom Manage 2006;31:85-95.

6. Davidson JR, MacLean AW, Brundage MD, et al. Sleep disturbance in cancer patients. Soc Sci Med 2002;54:1309-1321.

7. Savard J, Morin CM. Insomnia in the context of cancer: a review of a neglected problem. J Clin Oncol 2001;19:895-908.

8. American Psychiatric Association. Diagnostic and Statistical Manual of Mental Disorders, 4th Text Revision: DSM-IV-TR. Washington, DC: American Psychiatric Association; 2000.

9. Devine EB, Hakim Z, Green J. A systematic review of patient-reported outcome instruments measuring sleep dysfunction in adults. Pharmacoeconomics 2005;23:889-912.

10. Lee KA, Ward TM. Critical components of a sleep assessment for clinical practice settings. Issues Ment Health Nurs 2005;26:739-750.

11. Savard $\mathrm{MH}$, Savard J, Simard $\mathrm{S}$, et al. Empirical validation of the Insomnia Severity Index in cancer patients. Psychooncology 2005;14:429-441.

12. Berger A, Parker K, Young-McCaughan S, et al. Sleep wake disturbances in people with cancer and their caregivers: state of the science. Oncol Nurs Forum 2005;32:E98-E126.

13. National Cancer Institute. Sleep Disorders (PDQ ${ }^{\circledR}$ ) $2 / 16 / 2006$. Available at: http://www.cancer.gov/cancertopics/pdq/supportivecare/ sleepdisorders/healthprofessional/. Accessed September 26, 2007.

14. Buysse DJ, Ancoli-Israel S, Edinger JD, et al. Recommendations for a standard research assessment of insomnia. Sleep 2006;29:1155-1173.

15. Lee KA. Impaired sleep. In: Carrieri-Kohlman V, Lindsey A, West C, eds. Pathophysiological Phenomena in Nursing, 3rd ed. St. Louis, MO: Saunders; 2003:363-385.

16. Spielman AJ, Glovinsky P. A conceptual framework of insomnia for primary care practitioners: predisposing, precipitating and perpetuating factors. Sleep Medicine Alerts 2004;9:1-6.

17. Borbely AA, Achermann P. Sleep homeostasis and models of sleep regulation. J Biol Rhythms 1999;14:557-568. 
18. Vena C, Parker K, Cunningham M, et al. Sleep-wake disturbances in people with cancer part I: an overview of sleep, sleep regulation, and effects of disease and treatment. Oncol Nurs Forum 2004;31: 735-746.

19. Payne JK. A neuroendocrine-based regulatory fatigue model. Biol Res Nurs 2004;6:141-150.

20. Bower JE, Ganz PA, Dickerson SS, et al. Diurnal cortisol rhythm and fatigue in breast cancer survivors. Psychoneuroendocrinology 2005;30:92-100.

21. Dantzer R, Kelley KW. Twenty years of research on cytokine-induced sickness behavior. Brain Behav Immun 2007;21:153-160.

22. Lee BN, Dantzer R, Langley KE, et al. A cytokine-based neuroimmunologic mechanism of cancer-related symptoms. Neuroimmunomodulation 2004;11:279-292.

23. Payne JK. A neuroendocrine-based regulatory fatigue model. Biol Res Nurs 2004;6:141-150.

24. Bower JE. Cancer-related fatigue: links with inflammation in cancer patients and survivors. Brain Behav Immun 2007;21:863-871.

25. Ryan JL, Carroll JK, Ryan EP, et al. Mechanisms of cancer-related fatigue. Oncologist 2007;12(Suppl 1):22-34.

26. Wood LJ, Nail LM, Gilster A, et al. Cancer chemotherapy-related symptoms: evidence to suggest a role for proinflammatory cytokines. Oncol Nurs Forum 2006;33:535-542.

27. Berger AM, Sankaranarayanan J, Watanabe-Galloway S. Current methodological approaches to the study of sleep disturbances and quality of life in adults with cancer: a systematic review. Psychooncology 2007;16:401-420.

28. American Academy of Sleep Medicine. International Classification of Sleep Disorders: Diagnostic \& Coding Manual, 2nd ed. Westchester, IL: American Academy of Sleep Medicine; 2005.

29. Carpenter JS, Elam JL, Ridner SH, et al. Sleep, fatigue, and depressive symptoms in breast cancer survivors and matched healthy women experiencing hot flashes. Oncol Nurs Forum 2004;31:591-598.

30. NIH. National Institutes of Health State of the Science Conference statement on Manifestations and Management of Chronic Insomnia in Adults, June 13-15, 2005. Sleep 2005;28:1049-1057.

31. Alfano CM, Rowland JH. Recovery issues in cancer survivorship: a new challenge for supportive care. Cancer J 2006;12:432-443.

32. Bardwell WA, Profant J, Casden DR, et al. The relative importance of specific risk factors for insomnia in women treated for early-stage breast cancer. Psychooncology 2007; epub ahead of print.

33. Johns MW. A new method for measuring daytime sleepiness: the Epworth sleepiness scale. Sleep 1991;14:540-545.

34. Ancoli-Israel S. Sleep and fatigue in cancer patients. In: Kryger MH, Roth T, Dement WC, eds. Principles and Practice of Sleep Medicine. Philadelphia: Saunders; 2005:1218-1224.

35. Roscoe JA, Kaufman ME, Matteson-Rusby SE, et al. Cancer-related fatigue and sleep disorders. Oncologist 2007:12(Suppl 1):35-42.

36. Barton-Burke M. Cancer-related fatigue and sleep disturbances. Cancer Nurs 2006;29;2(Suppl 2):72-77.

37. de Jong N, Courtens AM, Abu-Saad HH, et al. Fatigue in patients with breast cancer receiving adjuvant chemotherapy: a review of the literature. Cancer Nurs 2002;25:283-297; quiz 298-289.

38. Donovan KA, Jacobsen PB. Fatigue, depression, and insomnia: evidence for a symptom cluster in cancer. Semin Oncol Nurs 2007; 23:127-135.

39. Fiorentino L, Ancoli-Israel S. Insomnia and its treatment in women with breast cancer. Sleep Med Rev 2006;10:419-429.
40. Lee K, Cho M, Miaskowski C, et al. Impaired sleep and rhythms in persons with cancer. Sleep Med Rev 2004;8:199-212.

41. Theobald DE. Cancer pain, fatigue, distress, and insomnia in cancer patients. Clin Cornerstone 2004;6(Suppl 1D):S15-21.

42. Ancoli-Israel S, Liu L, Marler MR, et al. Fatigue, sleep, and circadian rhythms prior to chemotherapy for breast cancer. Support Care Cancer 2006;14:201-209.

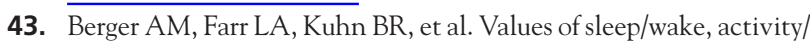
rest, circadian rhythms, and fatigue prior to adjuvant breast cancer chemotherapy. J Pain Symptom Manage 2007;33:398-409.

44. Jacobsen PB, Hann DM, Azzarello LM, et al. Fatigue in women receiving adjuvant chemotherapy for breast cancer: characteristics, course, and correlates. J Pain Symptom Manage 1999;18: 233-242.

45. Berger AM, Farr L. The influence of daytime inactivity and nighttime restlessness on cancer-related fatigue. Oncol Nurs Forum 1999;26:1663-1671.

46. Kuo HH, Chiu MJ, Liao WC, et al. Quality of sleep and related factors during chemotherapy in patients with stage I/II breast cancer. J Formos Med Assoc 2006;105:64-69.

47. Barton-Burke M. Cancer-related fatigue and sleep disturbances. Further research on the prevalence of these two symptoms in longterm cancer survivors can inform education, policy, and clinical practice. Am J Nurs 2006;106(Suppl 3):72-77.

48. Bower JE, Ganz PA, Desmond KA, et al. Fatigue in breast cancer survivors: occurrence, correlates, and impact on quality of life. J Clin Oncol 2000;18:743-753.

49. Broeckel JA, Jacobsen PB, Horton J, et al. Characteristics and correlates of fatigue after adjuvant chemotherapy for breast cancer. J Clin Oncol 1998;16:1689-1696.

50. Servaes P, Verhagen C, Bleijenberg G. Fatigue in cancer patients during and after treatment: prevalence, correlates and interventions. Eur J Cancer 2002;38:27-43.

51. Buysse DJ, Reynolds CF, Monk TH, et al. The Pittsburgh Sleep Quality Index: a new instrument for psychiatric practice and research. Psychiatry Res 1989;28:193-213.

52. Miaskowski C, Lee KA. Pain, fatigue, and sleep disturbances in oncology outpatients receiving radiation therapy for bone metastasis: a pilot study. J Pain Symptom Manage 1999;17:320-332.

53. Mystakidou K, Parpa E, Tsilika E, et al. Sleep quality in advanced cancer patients. J Psychosom Res 2007;62:527-533.

54. Berger AM. Patterns of fatigue and activity and rest during adjuvant breast cancer chemotherapy. Oncol Nurs Forum 1998;25:51-62.

55. Berger AM, Higginbotham P. Correlates of fatigue during and following adjuvant breast cancer chemotherapy: a pilot study. Oncol Nurs Forum 2000;27:1443-1448.

56. Roscoe JA, Morrow GR, Hickok JT, et al. Temporal interrelationships among fatigue, circadian rhythm and depression in breast cancer patients undergoing chemotherapy treatment. Support Care Cancer 2002;10:329-336.

57. Levin RD, Daehler MA, Grutsch JF, et al. Circadian function in patients with advanced non-small-cell lung cancer. Br J Cancer 2005;93:1202-1208.

58. Rich T, Innominato PF, Boerner J, et al. Elevated serum cytokines correlated with altered behavior, serum cortisol rhythm, and dampened 24-hour rest-activity patterns in patients with metastatic colorectal cancer. Clin Cancer Res 2005;11:1757-1764.

59. Glaus A, Boehme CH, Thürlimann B, et al. Fatigue and menopausal symptoms in women with breast cancer undergoing hormonal cancer treatment. Ann Oncol 1006;17:801-806. 
Berger and Mitchell

60. Given B, Given C, Azzouz F, et al. Physical functioning of elderly cancer patients prior to diagnosis and following initial treatment. Nurs Res 2001;50:222-232.

61. Fox SW, Lyon D, Farace E. Symptom clusters in patients with high-grade glioma. J Nurs Scholarsh 2007;39:61-67.

62. Barsevick AM, Dudley WN, Beck SL. Cancer-related fatigue, depressive symptoms, and functional status: a mediation model. Nurs Res 2006;55:366-372.

63. Morin CM, Bootzin RR, Buysse DJ, et al. Psychological and behavioral treatment of insomnia: update of the recent evidence (1998-2004). Sleep 2006;29:1398-1414.

64. Morgenthaler T, Kramer M, Alessi C, et al. Practice parameters for the psychological and behavioral treatment of insomnia: an update. An American Academy of Sleep Medicine report. Sleep 2006;29: 1415-1419.

65. Sackett DL. Rules of evidence and clinical recommendations for the management of patients. Can J Cardiol 1993;9:487-489.

66. Barton S, ed. Clinical Evidence Concise: The International Source of the Best Available Evidence for Effective Health Care, 7th ed. Kingsport, TN: BMJ Publishing Group; 2002.

67. Mitchell SA, Friese CR. Weight of evidence. Available at: http://www.ons.org/outcomes/tables/documents/woevidence.pdf. Accessed September 26, 2007.

68. Gobel BH, Beck SL, O'Leary C. Nursing-sensitive patient outcomes: the development of the putting evidence into practice resources for nursing practice. Clin J Oncol Nurs 2006;10:621-624.

69. Mitchell SA, Beck SL, Hood LE, et al. Putting evidence into practice: evidence-based interventions for fatigue during and following cancer and its treatment. Clin J Oncol Nurs 2007;11:99-113.

70. Page MS, Berger AM, Johnson LB. Putting evidence into practice: evidence-based interventions for sleep-wake disturbances. Clin J Oncol Nurs 2006;10:753-767.

71. Morin CM, Culbert JP, Schwartz SM. Nonpharmacological interventions for insomnia: a meta-analysis of treatment efficacy. Am J Psychiatry 1994;151:1172-1180.

72. Belanger L, Savard J, Morin CM. Clinical management of insomnia using cognitive therapy. Behav Sleep Med 2006;4:179-198.

73. Szuba MP, Kloss JE, Dinges DF. Insomnia Principles and Management. New York: Cambridge University Press; 2003.

74. Currie SR, Wilson KG, Pontefract AJ, et al. Cognitive-behavioral treatment of insomnia secondary to chronic pain. J Consult Clin Psycho 2000;68:407-416.

75. Lichstein KL, Wilson NM, Johnson CT. Psychological treatment of secondary insomnia. Psychol Aging 2000;15:232-240.

76. Currie SR, Clark S, Hodgins DC, et al. Randomized controlled trial of brief cognitive-behavioural interventions for insomnia in recovering alcoholics. Addiction 2004;99:1121-1132.

77. Rybarczyk B, Lopez M, Benson R, et al. Efficacy of two behavioral treatment programs for comorbid geriatric insomnia. Psychol Aging 2002;17:288-298.

78. Berger AM, VonEssen S, Kuhn BR, et al. Feasibility of a sleep intervention during adjuvant breast cancer chemotherapy. Oncol Nurs Forum 2002;29:1431-1441.

79. Berger AM, Von Essen S, Kuhn BR, et al. Adherence, sleep, and fatigue outcomes after adjuvant breast cancer chemotherapy: results of a feasibility intervention study. Oncol Nurs Forum 2003;30: 513-522.

80. Davidson JR, Waisberg JL, Brundage MD, et al. Nonpharmacologic group treatment of insomnia: a preliminary study with cancer survivors. Psychooncology 2001;10:389-397.
81. Quesnel C, Savard J, Simard S, et al. Efficacy of cognitivebehavioral therapy for insomnia in women treated for nonmetastatic breast cancer. J Consult Clin Psychol 2003;71:189-200.

82. Savard J, Simard S, Ivers H, et al. Randomized study on the efficacy of cognitive-behavioral therapy for insomnia secondary to breast cancer, part I: sleep and psychological effects. J Clin Oncol 2005;23:6083-6096.

83. Carlson LE, Garland SN. Impact of mindfulness-based stress reduc tion (MBSR) on sleep, mood, stress and fatigue symptoms in cancer outpatients. Int J Behav Med 2005;12:278-285.

84. Kim Y, Roscoe JA, Morrow GR. The effects of information and negative affect on severity of side effects from radiation therapy for prostate cancer. Support Care Cancer 2002;10:416-421.

85. Mock V, Dow $\mathrm{KH}$, Meares CJ, et al. Effects of exercise on fatigue, physical functioning, and emotional distress during radiation therapy for breast cancer. Oncol Nurs Forum 1997;24: 991-1000

86. Culpepper L. Secondary insomnia in the primary care setting: review of diagnosis, treatment, and management. Curr Med Res Opin 2006;22:1257-1268.

87. Hirst A, Sloan R. Benzodiazepines and related drugs for insomnia in palliative care. Cochrane Database Syst Rev 2004;4:CD003346.

88. Taibi DM, Landis CA, Petry $\mathrm{H}$, et al. A systematic review of valerian as a sleep aid: safe but not effective. Sleep Med Rev 2007;11 209-230.

89. Bain KT. Management of chronic insomnia in elderly persons. Am J Geriatr Pharmacother 2006;4:168-192.

90. Dolder C, Nelson M, McKinsey J. Use of non-benzodiazepine hypnotics in the elderly: are all agents the same? CNS Drugs 2007;21 389-405.

91. Dundar Y, Dodd S, Strobl J, et al. Comparative efficacy of newer hypnotic drugs for the short-term management of insomnia: a systematic review and meta-analysis. Hum Psychopharmacol 2004;19: 305-322.

92. Glass J, Lanctot KL, Herrmann N, et al. Sedative hypnotics in older people with insomnia: meta-analysis of risks and benefits. BMJ 2005;331:1169-1173.

93. Bruera E, Driver L, Barnes EA, et al. Patient-controlled methylphenidate for the management of fatigue in patients with advanced cancer: a preliminary report. J Clin Oncol 2003;21:4439-4443.

94. Bruera E, Strasser F, Shen L, et al. The effect of donepezil on sedation and other symptoms in patients receiving opioids for cancer pain: a pilot study. J Pain Symptom Manage 2003;26: 1049-1054.

95. Bruera E, Valero V, Driver L, et al. Patient-controlled methylphenidate for cancer fatigue: a double-blind, randomized, placebo-controlled trial. J Clin Oncol 2006;24:2073-2078.

96. Cullum JL, Wojciechowski AE, Pelletier G, et al. Bupropion sustained release treatment reduces fatigue in cancer patients. Can J Psychiatry 2004;49:139-144.

97. Hanna A, Sledge G, Mayer ML, et al. A phase II study of methylphenidate for the treatment of fatigue. Support Care Cancer 2006;14:210-215.

98. Moss EL, Simpson JS, Pelletier G, et al. An open-label study of the effects of bupropion SR on fatigue, depression and quality of life of mixed-site cancer patients and their partners. Psychooncology 2006;15:259-267.

99. Sarhill N, Walsh D, Nelson KA, et al. Methylphenidate for fatigue in advanced cancer: a prospective open-label pilot study. Am J Hosp Palliat Care 2001;18:187-192. 
Cancer-Related Fatigue and Sleep Quality

100. Schwartz AL, Thompson JA, Masood N. Interferon-induced fatigue in patients with melanoma: a pilot study of exercise and methylphenidate. Oncol Nurs Forum 2002;29:E85-E90.

101. Shaw EG, Rosdhal R, D'Agostino RB Jr, et al. Phase II study of donepezil in irradiated brain tumor patients: effect on cognitive function, mood, and quality of life. J Clin Oncol 2006;24:1415-1420.

102. Sugawara $Y$, Akechi T, Shima Y, et al. Efficacy of methylphenidate for fatigue in advanced cancer patients: a preliminary study. Palliat Med 2002;16:261-263.

103. Capuron L, Gumnick JF, Musselman DL, et al. Neurobehavioral effects of interferon-alpha in cancer patients: phenomenology and paroxetine responsiveness of symptom dimensions. Neuropsychopharmacology 2002;26:643-652.

104. Morrow GR, Hickok JT, Roscoe JA, et al. Differential effects of paroxetine on fatigue and depression: a randomized, double-blind trial from the University of Rochester Cancer Center Community Clinical Oncology Program. J Clin Oncol 2003;21:4635-4641.

105. Roscoe JA, Morrow GR, Hickok JT, et al. Effect of paroxetine hydrochloride (Paxil) on fatigue and depression in breast cancer patients receiving chemotherapy. Breast Cancer Res Treat 2005;89:243-249.

106. Weitzner MA, Moncello J, Jacobsen PB, et al. A pilot trial of paroxetine for the treatment of hot flashes and associated symptoms in women with breast cancer. J Pain Symptom Manage 2002;23: 337-345.

107. Caraceni A, Simonetti F. Psychostimulants: new concepts for palliative care from the modafinil experience? J Pain Symptom Manage 2004;28:97-99.

108. Cox JM, Pappagallo M. Modafinil: a gift to portmanteau. Am J Hosp Palliat Care 2001;18:408-410.

109. Prommer E. Modafinil: is it ready for prime time? J Opioid Manag 2006;2:130-136.

110. Rivera VM. Modafinil for the treatment of diminished responsiveness in a patient recovering from brain surgery. Brain Inj 2005;19:725-727.

111. Spathis A, Morrish E, Booth S, et al. Selective circadian rhythm disturbance in cerebral lymphoma. Sleep Med 2003;4:583-586.

112. Torta R, Berra $C$, Binaschi $L$, et al. Amisulpride in the short-term treatment of depressive and physical symptoms in cancer patients during chemotherapies. Support Care Cancer 2007;15:539-546.

113. Food and Drug Administration. (March 14, 2007). FDA News, March 14, 2007. Available at: http://www.fda.gov/bbs/topics/NEWS/ 2007/NEW01587.html. Accessed September 26, 2007.

114. Mayers AG, Baldwin DS. Antidepressants and their effect on sleep. Hum Psychopharmacol 2005;20:533-559. 